\title{
THE EFFICACY OF THE SimPlified AIR CUSHION (SAC) COMPARED TO THE POLYURETHANE FOAM CUSHION WITH REGARD TO ISCHIAL TUBEROSITY INTERFACE PRESSURE RELIEF
}

\begin{abstract}
This study was initiated in an attempt to compare the Simplified air cushion (SAC) with the Polyurethane Foam (PU Foam) wheelchair cushion with regard to effective pressure relief The study focused especially on the wheelchair bound spinal cord injured (SCI) patient.

VISSER C, M Phys T (research) (UP) EKSTEEN CA, PhD (UP)

'Department of Physiotherapy, University of Pretoria

Thirty ulcer-free spinal cord injured (SCI) patients participated in this study. Patients were tested on a novice wheelchair cushion, namely the (SAC) as well as on the high-density PU Foam cushion, currently used in government subsidised hospitals. Ischial tuberosity interface pressures were measured under both ischial tuberosities by means of the Oxford Pressure Monitor MK 11 (OPM MKII).

Maximum average pressures on the SAC were $73.60 \mathrm{mmHg}$ and $82.97 \mathrm{mmHg}$ on the PU Foam cushion. The results suggest that the SAC provides adequate pressure relief if compared to the PU Foam cushion. Due to the fact that the $S A C$ is designed on the same principles as other air cushions, it provides a maximum support area which distributes the weight of the patient evenly, thereby lowering peak pressures. The SAC also has the ability to allow air circulation at the body interface, which aids in temperature control.
\end{abstract}

KEYWORDS: SPINAL CORD INJURY, PRESSURE ULCERS, ISCHIAL TUBEROSITY INTERFACE PRESSURE, SAC.

\section{INTRODUCTION}

Pressure ulcers are documented in Biblical passages and medical literature from as early as 2500 B.C (Jiricka et al 1995). Although there are multiple factors contributing to the formation of pressure ulcers, many authors agree that the cause of a pressure ulcer is mainly attributed to prolonged pressure over an area of soft tissue covering a bony prominence such as the ischial tuberosities, greater trochanters, sacrum and heels (Kernozek et al 1998). Of all the mentioned areas, the ischial tuberosities and sacrum are the most dangerous because of the potential of infection of the pelvic bones.

The wheelchair-bound spinal cord injured (SCI) patient is especially susceptible to pressure ulcer formation, due to prolonged pressure in the abovementioned areas.

Kosiak (1961) and Reswick (1976) are two of the pioneer researchers on the role of prolonged pressure in pressure ulcer formation. These two authors stated that pressure higher than $35 \mathrm{mmHg}$ applied to the body surface results in closure of the capillary circulation and the development of a pressure ulcer. Dinsdale (1973) and later Daniel (1981) investigated the amount of pressure needed to cause soft tissue damage, resulting in pressure ulcers in experimental animals. Daniel (1981) concluded from his study that muscle damage occurs at high pressure-short duration (500 $\mathrm{mmHg}, 4$ hours) whereas skin destruction requires high pressure-long duration $(800 \mathrm{mmHg}, 8$ hours). The author also stated that a single prolonged episode is not the only cause of a pressure ulcer but that shear forces between the supporting surface and the skin and underlying tissue, moisture on the supporting surface as well as the temperature between the patient and the supporting surface, contribute to pressure ulcer formation.

In the latest research on the effect on prolonged pressure on skin, Salcido $(1993,1994)$ indicated that $45 \mathrm{mmHg}$ is needed to result in closure of the capillary circulation with necrosis of the skin and the formation of a pressure ulcer.

The wheelchair-cushion performs a vital role in the prevention of pressure ulcers as one of the many devices reducing interface pressure between the patient and the supporting surface. A wide variety of cushions are currently available on the market such as air, foam, water, gel and foam cushions. Some of these cushions are very expensive and therefore State subsidised institutions are forced to make use of cheaper, and not necessarily the most effective pressure relieving cushion.

Despite advances in medicine and research, pressure ulcers remain a major cause of morbidity and mortality in the SCI patient. During the last decade, South Africa experienced one of the highest levels of criminal violence and motor vehicle accidents in the world. These factors have generated a significant

CORRESPONDENCE:

$C$ Visser, CA Eksteen

Faculty of Medicine Department of Physiotherapy

University of Pretoria PO Box 667 Pretoria 0001

South Africa

Tel (012) 354-2023

Fax (012) 3541226 
sector of our society which is disabled and wheelchair-bound. It is estimated that there are more than five million physical disabled South Africans, most of whom come from a historically disadvantaged background (Bell 1997).

The financial implication of recurring pressure ulcers, as well as the high cost of wheelchair cushions available (excluding the Polyurethane Foam [PU Foam] cushion) leads to the question of whether it is possible to invent a locally designed and manufactured cushion which is inexpensive, easy-to-make and operate, and which will match or exceed the pressure relieving properties of the Polyurethane Foam cushion. A simplified air cushion (SAC) was invented to meet this need.

The purpose of this study was to investigate the efficacy of the SAC, compared to the PU Foam cushion with regard to the relief of ischial tuberosity interface pressure.

\section{MATERIALS AND METHODS.}

\subsection{Materials}

\subsubsection{Description of the SAC.}

(Figure 1)

The SAC consists of four empty vacolitre-bags ( $1000 \mathrm{ml}$.) and a pressure unit. The bags are inflated and arranged in parallel. The vacolitre-bags are interconnected by a common header of plastic flexible tubing on the nozzle's side of the bags, which in turn, is connected to the pressure unit. There is a free flow of air between the airbags which causes it to alternately inflate and deflate partially as the patient moves on them until some state of equilibrium is reached. The SAC works on the same principle as other air cushions namely that by increasing the area of support and distributing the body weight more evenly over the seating surface, interface pressure is relieved more effectively.

The pressure unit by which the vacolitre bags are inflated, consists of a manual pump, similar to that of a sphygmomanometer, with a unidirectional flow control valve and a small pressure indicator that indicates the amount of internal pressure (inside the cushion) needed to provide effective pressure relief. The unidirectional flow control valve prevents the air escaping from the vacolitre bags once it is inflated.
The cushion cover is made of a cotton material, divided into 4 separate compartments for the vacolitre-bags to fit into. The compartments of the cotton cover, acts as pillowcases for the vacolitre bags. The cover is not padded.

\subsubsection{The Oxford Pressure Monitor MK11 (OPM MK11) (Picture 1)}

Ischial tuberosity interface pressures were measured by means of the Oxford pressure monitor MK11, which is a measuring device for multi-point assessment of interface pressure. It consists of two 3 by 4 cell-matrixes containing 12 cells each. The unit for measurement is $\mathrm{mmHg}$.

\subsection{Testing procedure}

Thirty SCI patients participated in the study. The group consisted of 27 males and 3 females with a mean age of 28 years and a range from 19 to 57 years. Mean body weight was $65,2 \mathrm{~kg}$ with a range from 50 to $100 \mathrm{~kg}$. None of the patients had any pressure ulcers and all of the patients were diagnosed to have complete lesions. Patients were tested using both cushions. Each cushion was positioned in a standard wheelchair for the interface pressure to be tested.

The patients were positioned in a neutral position in the wheelchair. The neutral position is known as the position where

\section{FIGURE 1: DESCRIPTION OF THE SAC. PROTOTYPE ONE (1)}

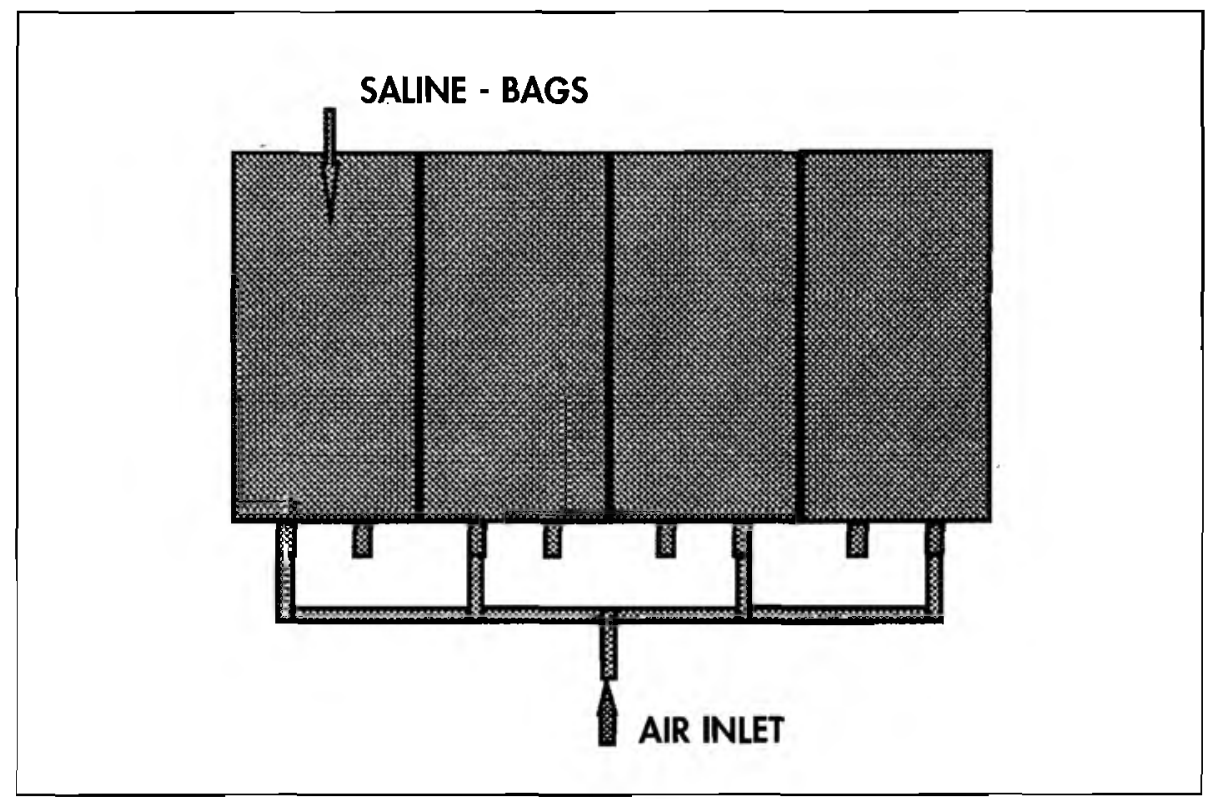

\section{PICTURE 1: THE OXFORD PRESSURE MONITOR MK1 1 (OPM MK11)}

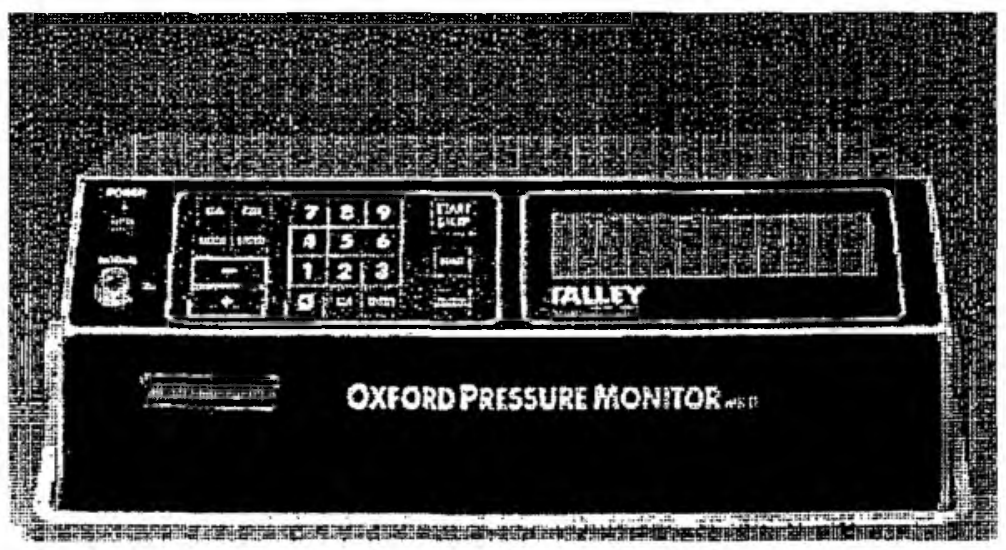


the hips and knees are flexed to $90^{\circ}$ with the feet supported on foot plates.

The matrixes of the OPM MK11 were fixed onto the surface of the cushion being tested, so that their positions relative to a referred axis would remain constant. Each cell matrix was placed on the cushion in such a way that the ischial tuberosities of all patients would fall on the back two row of cells.

The testing time for each cushion was as follows:

Total testing time for the SAC consisted of

- An initial 2-minute test on each ischial tuberosity, to determine the optimal intra-apparatus pressure (pressure inside the cushion) where the ischial tuberosity interface pressure would be at its lowest.

- A second 2 - minute test during which the maximum ischial tuberosity interface pressure reading was determined. During this test the intra-apparatus pressure is constant,

The testing time for the PU Foam was as follows:

- A 2 - minute test was performed to determine the ischial tuberosity interface pressure.

All these tests were performed on both ischial tuberosities of every patient.

The highest ischial tuberosity interface pressure readings, irrespective of side, were used for analysis.

\section{RESULTS}

The mean(SD) pressures under the ischial tuberosity were 73.60 (14.63) for the SAC and 82.97 (33.12) for the PU

TABLE 1: SUMMARY OF DATA

\begin{tabular}{|l|c|c|}
\hline & SAC & PU FOAM \\
\hline Average (mean) mmHG & 73.60 & 82.97 \\
\hline Std Deviation & 14.63 & 33.12 \\
\hline Minimum & 45.00 & 40.00 \\
\hline Maximum & 98.00 & 193.00 \\
\hline Median & 72.50 & 77.00 \\
\hline S.E. & 2.67 & 6.05 \\
\hline 95\% Confidence limits & & \\
\hline Upper & 78.94 & 95.06 \\
\hline Lower & 68.26 & 70.87 \\
\hline Difference & 10.68 & 24.19 \\
\hline
\end{tabular}

Foam cushion. See Table I. The difference in interface pressure between the SAC and the PU Foam was not statistically significant $(p>0.05)$. The Wilcoxon matched pairs signed ranks test was used for the statistical analysis.

A more exact comparison of the two sets of data can be seen in Graph I In this graph each subject number corresponds to the number allocated to him/her at the beginning of the study. From this graph it can be seen that, of the results of 30 patients, the SAC had higher interface pressures than the PU Foam in only 1] of the $30(36.6 \%)$ patients.

\section{DISCUSSION}

The difference in average interface pressure between the SAC and PU Foam cushions was not statistically significant. This should be very carefully considered, however, since a problem of accurately measuring pressures over bony prominences has been documented in the literature (Patterson et al 1979). The Oxford pressure monitor, however, seems to be a reliable and durable device that provides reasonably accurate results within known limitations.

The PU Foam cushion provided less effective pressure relief of the two cushions tested, with an average pressure of $82.97 \mathrm{mmHg}$. This result corresponds with the findings of Bar (1991) who recorded 87,6 $\mathrm{mmHg}$ and Koo (1996) who measured a value of $76 \mathrm{mmHg}$.

From the results in graph 1 , the properties of Foam are clearly seen. The

\section{GRAPH 1: MAXIMUM AVERAGE INTERFACE PRESSURE VS. PATIENT NUMBER}

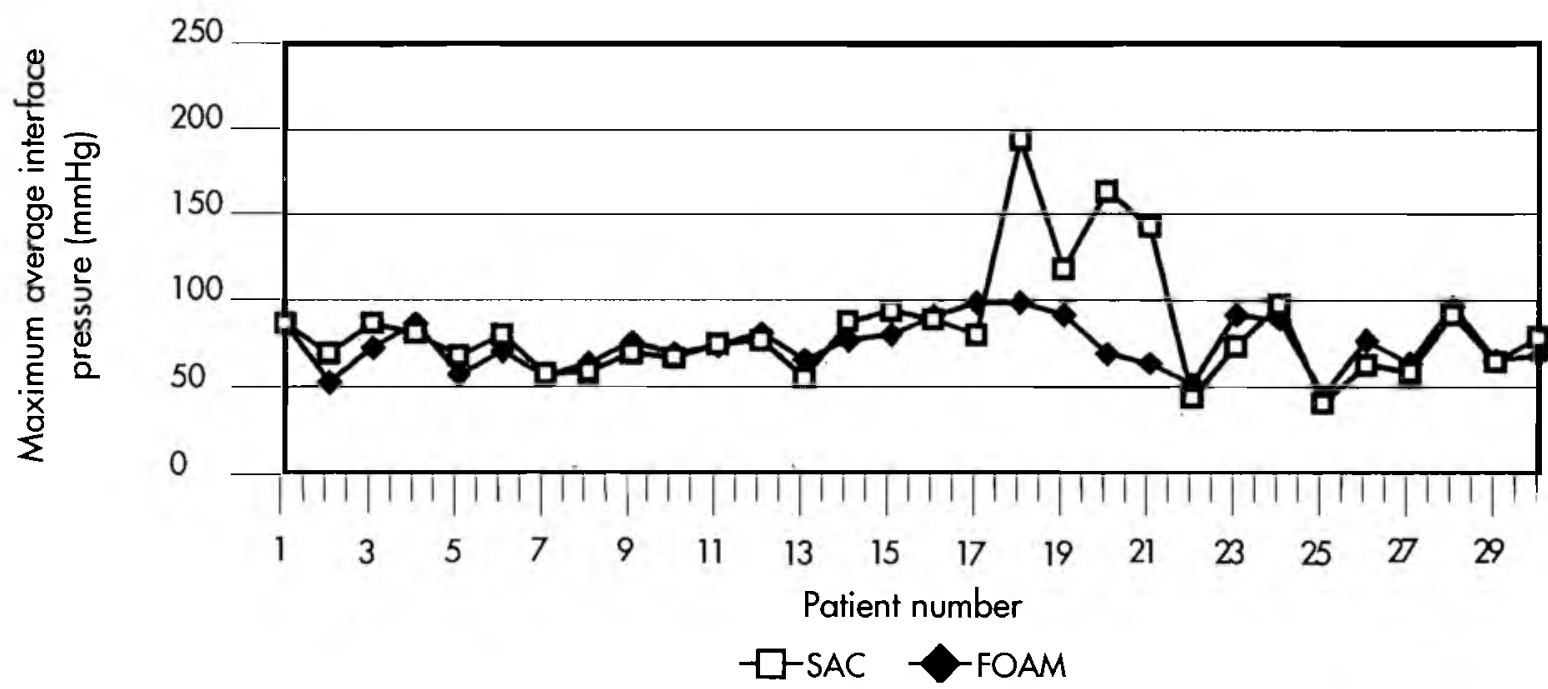


Foam cushion had both the lowest $(38,5 \mathrm{mmHg}$; patient 25$)$ and the highest (188 $\mathrm{mmHg}$; patient 18 ) readings of the two cushions being tested.

Furthermore the highest interface pressure difference between the left and the right ischial tuberosities (patient 20; left ischial tuberosity $163 \mathrm{mmHg}$ and $102 \mathrm{mmHg}$ on the right), was measured on the PU Foam cushion. The results of this study corresponds with the findings of Koo (1996) on the properties of PU Foam, concluding that PU Foam does not have the ability to distribute interface pressure as effectively as air cushions. The PU Foam cushion also has a limited lifespan and certain conditions such as high temperatures and continuous static loading of the PU Foam cushion may shorten the life of it drastically (Mc Fadyen 1980).

According to the results, the SAC provided the better pressure relief of the two cushions tested. The average interface pressure recorded on the SAC was $73.60 \mathrm{mmHg}$. This may be due to the design of the SAC which is based on the principle of providing a maximum support area which results in an even distribution of the patient's weight and thereby lowering peak pressures. The air inside the cushion also has the property of circulating freely, thereby assisting in temperature control between the patient and the SAC.

In conclusion it can be stated that this study was useful in the quest for an effective, inexpensive, easy-to-make and easy-to-operate cushion to reduce the problem of pressure ulcers in wheelchairbound SCI patients especially in the disadvantaged communities.

\section{QUALIFIED PHYSIOTHERAPISTS ARE IN DEMAND IN: CANADA, NEW ZEALAND AND AUSTRALIA}

If you are interested in moving ahead, we at Four Corners Emigration are specialists in

Personal and Business Migration.

Our international team of experts will guide you through the complex and constantly changing immigration regulations.

Allow one of our consultants to inform you of the different packages we offer.

We provide the most comprehensive advice and assistance on emigrating to the country of your choice.

We consult throughout South Africa.

\section{FourCorners e migration}

Registered Migration Agent No. 89880

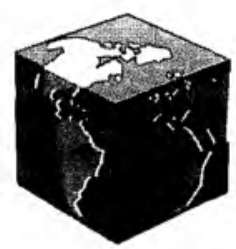

Johannesburg (011) 8815834 - Cape Town (021) 4650130 enquiries@4-corners.co.za

\section{REFERENCES}

1. Jiricka MK, Ryan P, Calvalho MA 1995 Pressure ulcer risk factors in an ICU population. Am J Crit Care 4:361

2. Kernozek TW, Lewin JE 1998 Seat interface pressures of individuals with paraplegia: Influence of dynamic wheelchair locomotion compared with static seated measurements. Arch Phys Med Rehabil 79:313-315

3. Kosiak M 1961 Etiology of decubitus ulcers. Arch Phys Med Rehabil 42:19-29

4. Reswick JB, Rogers J 1996 Experience at Rancho Los Amigos Hospital with devices and techniques to prevent pressure sores. In: Kenedi RM, Cowden JM, Scales JT. Bedsore biomechanics; London: McMillan 301-10

5. Dinsdale SM 1973 Decubitus ulcers in swine:light and electron microscopy study of pathogenesis. Arch Phys Med Rehabil $54: 51-56$

6. Daniel RK, Priest DL, Wheatley DC 1981: Etiologic factors in pressure sores: An experimental model. Arch Phys Med Rehabil $62: 492-497$

7. Salcido R, Carney J, Fisher S, et al 1993 A reliable animal model of pressure sore development: The role of free radicals. J Am Paraplegia Soc 16:61

8. Salcido R, Donofrio J J, Fisher S, et al 1994 Histopathology of pressure ulcers as a result of sequential computer-controlled pressure sessions in a fuzzy rat model. Adv Wound Care 7:23-40

9. Bell T 1997 Disabled ready to raise hullaballoo, Cape Times, Cape Town

10. Patterson RP and Fisher SC 1997 Accuracy of electrical transducers for measurement of pressure applied to skin: IEEE Trans Biomed Eng BME 26:450-456

11. McFadyen GM 1980 Polyurethane Foam wheelchair cushions: Retention of supportive properties Arch Phys Med Rehabil 61:234-237

12. Bar CA 1991 Evaluation of cushions using dynamic pressure measurement. Prost and Orth Int 15:232-240

13. Koo TKK, Mak AFT, Lee YL. 1996 Posture effect on seating interface biomechanics: Comparison between two seating cushions. Arch Phys Med Rehabil 77:40-47

14. Salcido R, Hart P, Smith A 1996 The prevention and management of pressure ulcers. In: Braddon RL (ed). Physical medicine and rehabilitation. I st ed. W.B. Saunders Company, Philadelphia pp 630-647 